Submission ID: 43761

\title{
Localization of Cavernous High-Capacity Interlayers in the UTM Riphean
}

Reservoir

A. Kozyaev* (KrasnoyarskNIPIneft-RN Co. Ltd), A. Merzlikina (KrasnoyarskNIPIneft-RN Co. Ltd), D. Petrov (KrasnoyarskNIPIneft-RN Co. Ltd), V. Shilikov (KrasnoyarskNIPIneft-RN Co. Ltd), A.

Tyzovskay (KrasnoyarskNIPIneft-RN Co. Ltd)

\section{SUMMARY}

We present a new approach to localization of the highly saturated zones of reservoir of rifei. The method is based on the processing of the scattered seismic energy. In this paper, we present the results obtained for an Eastern Siberian oilfield. 


\title{
Выявление перспективных зон для карбонатного коллектора по рассеянной составляющей сейсмического волнового поля
}

\author{
А.С. Мерзликина, А.А. Козяев, Д.А. Петров, В.В. Шиликов, А.А. Тузовский \\ (ООО «РН-КрасноярскНИПИнефть)
}

\begin{abstract}
Введение
В данной работе рассмотрен подход к прогнозу зон улучшенных коллекторских свойств карбонатного каверново-трещинного коллектора рифейского резервуара, на основе технологии специальной обработки и интерпретации рассеянной компоненты волнового поля (собственная разработка ООО «РН-КрасноярскНИПИнефть»). В работе представлены результаты анализа куба рассеянных волн, для одного из месторождений Восточной Сибири.

В виду отсутствия, на данный момент, технологии прогноза фильтрационно-емкостных свойств, по данным сейсморазведки, для такого типа коллекторов, применение рассеянных волн видится единственным возможным решением.
\end{abstract}

\section{Метод выделения рассеянной составляющей сейсмического волнового поля}

Начиная с 2009 года ООО «РН-КрасноярскНИПИнефть» занимается разработкой инновационных методов изучения трещиноватости карбонатных коллекторов, опираясь на выделение и обработку рассеянных сейсмических волн. На основе которых была создана технология «Выявления трещиновато-кавернозных резервуаров и определения их характеристик на основе инновационных методов обработки и интерпретации рассеянных волн» подтвержденная патентом, правообладатель интеллектуальной собственности - ПАО «НК «Роснефть».

Один из методов это - Фокусирующие преобразования (F-преобразования), которые позволяют выделять из поля пространственно-рассеянных волн энергетически выраженные объекты с аномальными сейсмоакустическими свойствами. Одним из основных преимуществ применения F-преобразований является возможность выявлять в разрезе деструктивные зоны по концентрации узлов дифракции или коротких, зачастую разно ориентированных, отражающих площадок [6].

Основная идея заключается в использовании конфигураций со скользящими системами (базами) источников возбуждения и приёмников колебаний, что позволяет формировать интерференционную систему с заданными характеристиками, а также настраивать (фокусировать) её на изучение конкретного типа волн и построения изображений локальных геологических объектов. Еще раз необходимо подчеркнуть, что суперпозиция селективных разрезов даёт возможность избирательного подавления регулярных отражений от гладких границ и статистического накапливания энергии рассеянных/дифрагированных волн [5].

\section{Выделение перспективных зон}

Месторождение расположено на территории Эвенкийского муниципального района Красноярского края. Геологический разрез подразделяется на три крупных структурностратиграфических мегакомплекса: раннепротерозойский фундамент, рифейский и вендкембрийский. Продуктивность доказана в вендских и рифеских отложениях. Наибольший промышленный интерес представляют преимущественно доломитизированные отложения рифейского возраста, с которыми связываются наибольшие объемы ресурсов УВ.

В результате проведенного динамического анализа волнового сейсмического поля и геологической интерпретации полученных результатов, удалось выполнить общий прогноз геологических характеристик продуктивных отложений вендских интервалов. Прогноз учитывает и хорошо согласуется с независимым анализом по ГИС и построенной ранее литофациальной моделью этих отложений [1].

Однако выполнить прогноз фильтрационно-емкостных свойств рифейского коллектора не удалось. На сегодняшний день, подхода, позволяющего решать задачу прогноза свойств, трещинно-кавернового рифейского коллектора, по данным сейсморазведки - не существует.

Отложения рифейского возраста с угловым несогласием перекрывают образования кристаллического фундамента. Распространение рифейских толщ в разрезе осадочного чехла 
находится в прямой зависимости от рельефа поверхности кристаллического фундамента: в пониженных участках - максимальные мощности, на выступах фундамента - минимальные, вплоть до полного отсутствия. Общая вскрытая скважинами толщина отложений рифейского комплекса достигает $3500 \mathrm{M.}$

Согласно принятой для территории Байкитской антеклизы стратиграфической схеме вскрытые скважинами отложения рифейского возраста подразделяются на ряд толщ, разрез которых слагают породы, существенно различающиеся по петрофизическим и фильтрационноемкостным свойствам. Коллектор каверново-трещинного, реже каверново-порово-трещинного типа. Средняя эффективная пустотность находится в районе $2 \%$, а проницаемость, обеспечиваемая, в основном системой естественных макротрещин может находится в диапазоне от первых мДарси до нескольких Дарси. ФЕС и литологический состав коллектора характеризуются крайней анизотропией и гетерогенностью.

Описанные выше свойства коллектора можно назвать не благоприятными для прогнозирования по сейсмическим данным. Пустотность рифейского коллектора слишком мала и слабо дифференцирована по разрезу, для того что бы оказать влияние на сейсмическое волновое поле. Литологический состав рифейского, можно прогнозировать лишь в первом приближении (более глинистые отложения или менее глинистые), на уровне разновозрастных толщ рифея.

Вследствие чего, необходим критерий прогноза зон с наилучшими фильтрационными свойствами карбонатной части рифейсих отложений. Таким инструментом предлагается использование разработанной в ООО "РН-КрасноярскНИПИнефть" технологии, базирующейся на выделении рассеянной компоненты волнового поля.

Для расчёта энергии рассеянных волн использовался, разработанный в ООО "РНКрасноярскНИПИнефть", пакет программ F-transform-2014 интегрированный в систему обработки данных сейсморазведки ProMAX/SS [2].

В результате расчета был получен общий куб поля рассеянных волн (ПЭРВ) для всей площади МОГТ-3Д. Карта представлена на рисунке 2.

Как уже было сказано, методика нацелена на обнаружение мелкомасштабных неоднородностей, которые в трещинно-каверновом коллекторе будут в первую очередь связаны с трещинами [4]. В качестве характеристики трещинного резервуара использовался коэффициент продуктивности, определенный по результатам ГДИ. Данные ГИС и керна не использовались для сопоставления, ввиду невозможности отделения закрытых и открытых трещин по этим исследованиям, а так же отсутствия информации по раскрытости трещин, что критически влияет на продуктивность трещинного резервуара. В свою очередь, ГДИ, при корректном проведении исследований, характеризует свойства пласта в прискважинной зоне. Предполагая, что притоки в скважине, в основном связаны с трещиноватостью, суммарная интенсивность и раскрытость трещин, предположительно, связана с коэффициентом продуктивности (Кпрод).

Вычленив два параметра - ПЭРВ и Кпрод, которые, хоть и не на прямую, но фиксируют степень трещиноватости пород рифейского резервуара были сопоставлены абсолютные значения этих величин. Для сопоставления использовалась полная выборка скважин, с корректно замерными значениями Кпрод (71 скважина). Для сейсмического параметра ПЭРВ в сравнении участвовало среднее значение амплитуды ПЭРВ в районе пластопересечения скважины с продуктивным пластом, для интервала от ОГ R0 вниз на 30 мс (средняя эффективная толщина). Результаты сопоставления десятичного логарифма Кпрод и ПЭРВ приведены в виде кросс-плотов на Рис. 1. Как можно заметить, наблюдается линейная зависимость с приемлемым коэффициентом корреляции $(0,81)$ между сравнимыми параметрами, но дисперсия регрессии недопустимо велика.

Для повышения прогнозной способности, исходная выборка была скорректирована. В первую очередь, исключены горизонтальные скважины (ГС). Продуктивность горизонтальных скважин зависит как от геологических, так и от технологических факторов. При испытании вертикальных скважин на месторождении применялись соляно-кислотные обработки пласта, которые позволяли снизить или полностью снять негативное воздействие на призабойную скважин в процессе бурения и освоения. В связи с отсутствием на месторождении флота ГНКТ солянокислотные обработки горизонтальных скважин не проводились. Отсутствие работ по 


\section{EAGE}

интенсификации притока в горизонтальных скважинах не позволяет определить начальную продуктивность и использовать результаты испытания ГС для построения зависимости.

Во вторых, исходя из общего представления о строении резервуара, а именно - различных ФЕС разновозрастных рифейских толщ, выборка была разделена по стратиграфической принадлежности объектов испытаний. Далее выполнено на юрубченскую толщу - наиболее изученную бурением и все остальные, более молодые толщи, ввиду непредставительной статистики для каждой из молодых толщ в отдельности.

В результате, после дополнительной проработки - частичного снятия технологических и геологических факторов, общая зависимость разделена на две: для юрубченской толщи и оставшихся, более молодых толщ рифея. Обе зависимости прямопропорциональные, линейные, характеризуются высокими коэффициентами корреляции между сравниваемыми параметрами $(0,87$ и 0,85 соответственно. По полученной регрессии был выполнен прогноз Кпрод (Рис. 3).
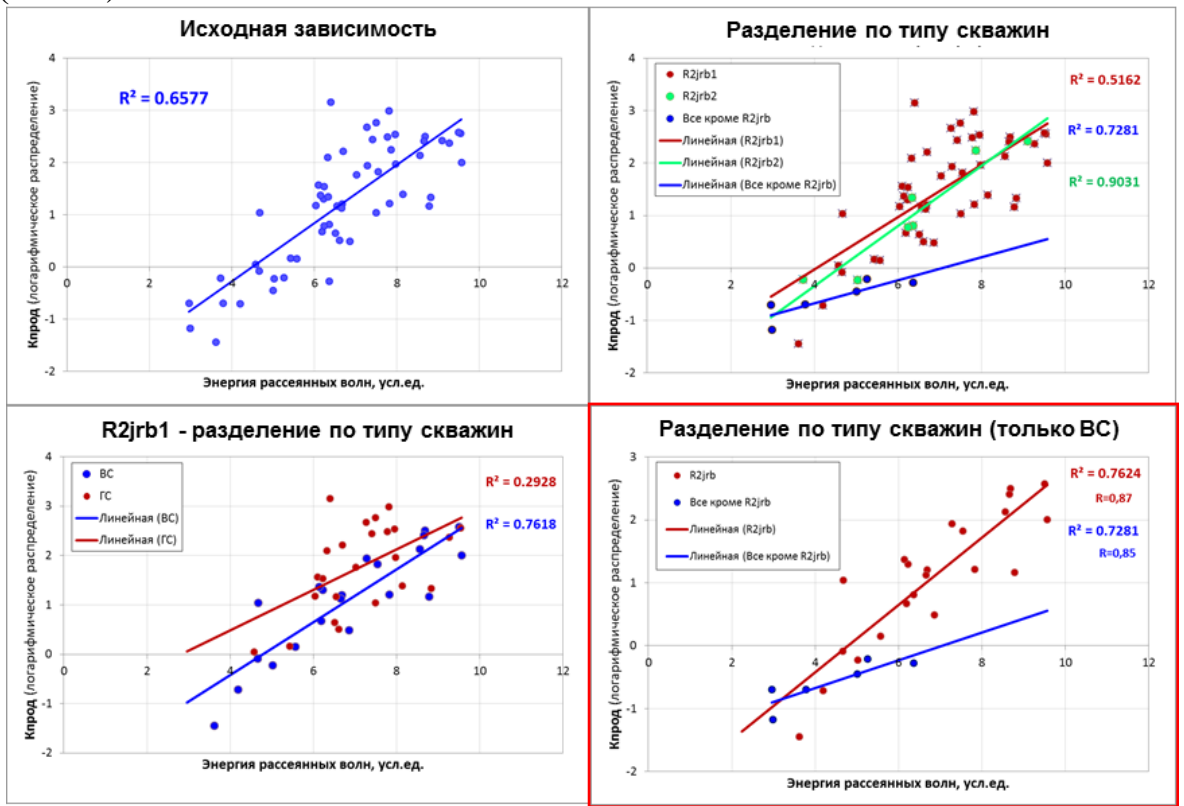

Рисунок 1 Кросс-плоты зависимости значения ПЭРВ и десятичного логарифма Кпрод

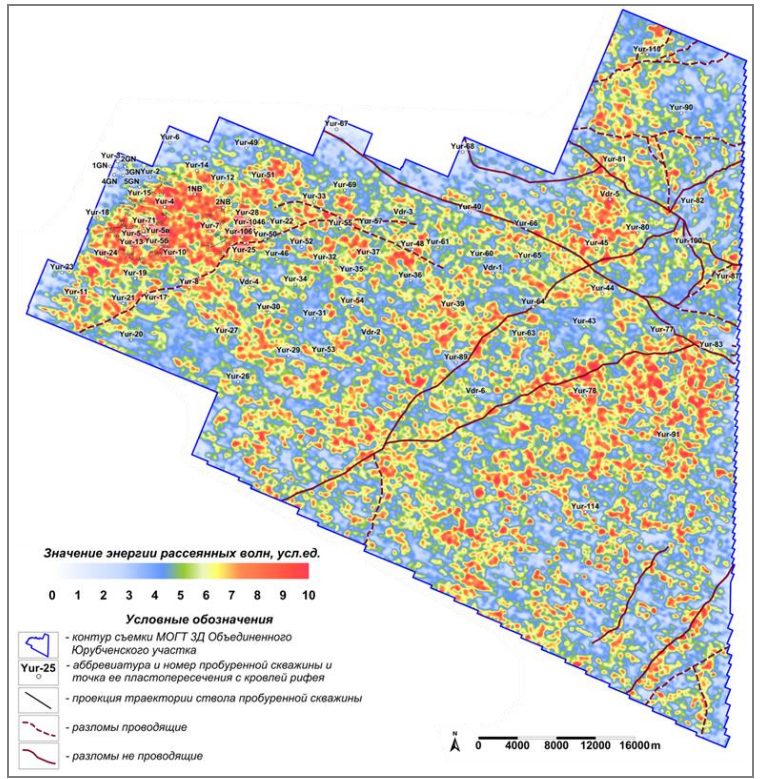

Рисунок 2 Схема распределения ПЭРВ в рифейском интервале

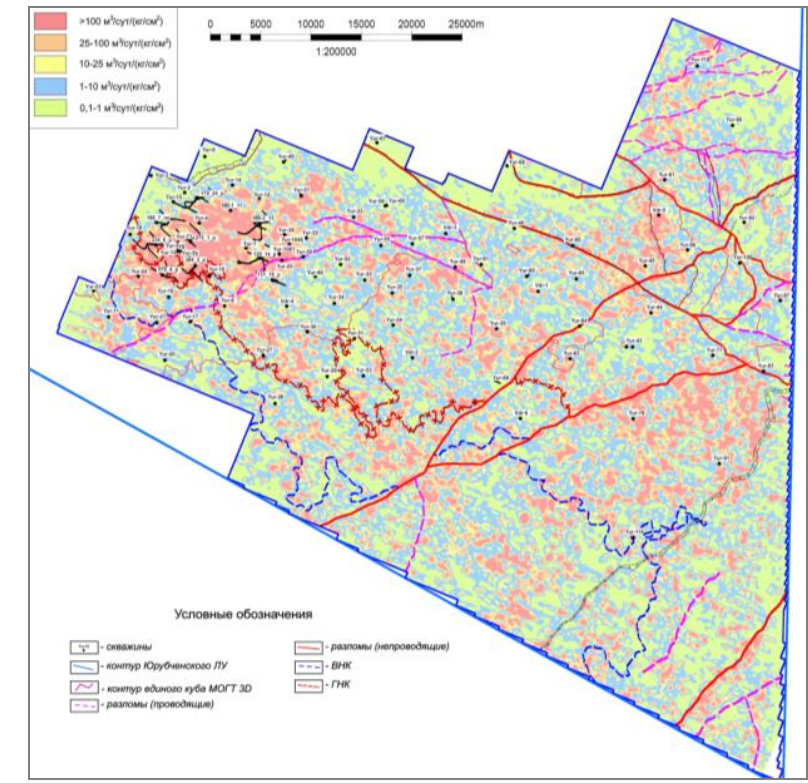

Рисунок 3 Прогнозная схема Кпрод для рифейского интервала 


\section{Выводы}

Для рифейской части разреза рекомендуется использование куба ПЭРВ (и прогнозной карты Кпрод) при построении геологической моделей, а именно, при распределении продуктивности. Применение полученных результатов позволит оптимизировать проектные решения по разработке и программу ГРР на месторождении.

\section{Библиография}

1. Ткачук Д.Н. Научно-технический отчет «Формирование, переработка и комплексная интерпретация единого куба данных МОГТ ЗД в пределах Юрубченского ЛУ ОАО «Востсибнефтегаз», г. Красноярск: ООО «РН-КрасноярскНИПИнефть», 2015 г.

2. Мерзликина А.С. Информационные отчеты 1-8 этапов по теме: «Развитие алгоритмов и создание методик и программных модулей технологии выявления трещиноватокавернозных резервуаров и определение их характеристик на основе методов сейсмической интерферометрии», г. Красноярск: ООО «РН-КрасноярскНИПИнефть», 2013 г.

3. Мерзликина А.С. Научно-технический отчет «Апробация технологии выявления трещиновато-кавернозных резервуаров на основе инновационных методов обработки и интерпретации рассеянных волн на лицензионных участках ОАО «НК «Роснефть»г. Красноярск: ООО «РН-КрасноярскНИПИнефть», 2015 г.

4. Мерзликина. А.С. Прогнозирование флюидонасыщенности пласта-коллектора на основе анализа рассеянной компоненты / А.С. Мерзликина [и. др.] // Совместный семинар EAGE/SPE геолого-геофизический мониторинг процесса разработки (Москва, 4 -6 марта 2013 г.). - М., 2013.

5. Поздняков В.А. «Отчет о разработке методики прогноза трещиноватости на основе фокусирующих преобразований» ООО «РН-КрасноярскНИПИнефть», г. Красноярск, 2011 г.

6. Поздняков В.А., Чеверда В.А. Фокусирующие преобразования сейсмических данных для площадных стационарных систем. «Геология и геофизика». 2005, № 5, с. 328 - 338 .

\section{References}

1. Tkachuk D.N. Scientific and technical report "Formation, processing and complex interpretation of a seismic data 3D within the Yurubchensky area of Vostsibneftegaz OJSC, Krasnoyarsk: RNKrasnoyarskNIPIneft LLC, 2015.

2. Merzlikina A.S. Informational reports of 1-8 stages on the theme: "Development of algorithms and creation of techniques and software modules for detection of fractured-cavernous reservoirs and determination of their characteristics on the basis of seismic interferometry methods", Krasnoyarsk: RN-KrasnoyarskNIPIneft LLC, 2013

3. Merzlikina A.S. Scientific and technical report "Testing of technology for revealing fracturedcavernous reservoirs on the basis of innovative methods for processing and interpreting scattered waves in licensed areas of OJSC" NK Rosneft ", Krasnoyarsk: RN-KrasnoyarskNIPIneft LLC, 2015.

4. Merzlikina. A.S. Forecasting the fluid saturation of the -reservoir on the basis of the analysis of the scattered waves. Merzlikina [and. Etc.] // EAGE / SPE workshop geological and geophysical monitoring of the development process (Moscow, March 4-6, 2013). - M., 2013.

5. Pozdnyakov V.A. "Report on the development of methods for fracture prediction based on focusing transformations" LLC "RN-KrasnoyarskNIPIneft", Krasnoyarsk, 2011.

6. Pozdnyakov VA, Cheverda V.A. Focusing transformations of seismic data for area stationary systems. "Geology and geophysics." 2005, No. 5, p. 328-338. 